\title{
Crucial ethical problem for Japanese nursing students at clinical settings
}

\author{
Mari Tsuruwaka * \\ College of Nursing, St. Luke's International University, Tokyo, Japan
}

Received: July 17, 2015

Accepted: August 17, 2015

Online Published: September 7, 2015

DOI: $10.5430 /$ jnep.v5n12p17

URL: http://dx.doi.org/10.5430/jnep.v5n12p17

\begin{abstract}
Background: Nursing students encounter ethical problems in their interactions with various people in clinical practice. In Japan, few studies have examined ethical problems between students and nursing educators in clinical practice. The aim of this study was to investigate the characteristics of ethical problems encountered by Japanese nursing students from the perspectives of patients and the students themselves.

Methods: A descriptive, exploratory study was employed in this research. Questionnaires were distributed to 274 third-year students who had completed 6 months of clinical practice in 2012, 2013, or 2014. The situations in which students described ethical problems were classified into those involving patients and their family members and those involving the students themselves and other trainees.

Results: A total of 58 students described 198 situations involving ethical problems ( 89 toward patients, 102 toward students, 7 other). Students expressed concern in terms of their basic attitudes toward nurses and respect for patient individuality. The largest number of unethical teaching behaviors involved violations of the principles of benevolence and respect for students.

Conclusions: The results suggest the need for student assistance in understanding ethical problems, for strengthening of links with intramural ethics education, for the establishment of a consultation system, and for leveraging of faculty development education.
\end{abstract}

Key Words: Ethical problem, Japanese nursing students, Clinical practice, Nursing education, Nursing ethics

\section{INTRODUCTION}

\subsection{Ethical problems encountered by nursing students in clinical practice-issues involving patients}

Studies have been undertaken in various countries on the ethical problems encountered by nursing students in clinical practice. One common theme identified by these studies is ethical problems involving health care professionals, ${ }^{[1-5]}$ many of which are derived from nursing staff. ${ }^{[1,2]}$

In studies conducted in the U.S. and South Korea using the same framework, common ethical problems involving health care professionals, specifically nursing staff, were as follows: they did not properly provide medications and treatments, they did not provide quality care, and they acted unprofessionally in terms of client confidentiality, etc. ${ }^{[1,2]}$ The U.S.-based study ${ }^{[1]}$ also showed that nursing staff engaged in force-feeding, while the South Korean study ${ }^{[2]}$ revealed discrepancies between what nursing students were taught in university and what nursing staff actually did in clinical practice, as well as inappropriate treatment of students in front of patients and family members.

Similar to the U.S.-based ${ }^{[1]}$ and South Korean-based ${ }^{[2]}$ stud-

\footnotetext{
*Correspondence: Mari Tsuruwaka; Email: tsuruwaka@ slcn.ac.jp; Address: College of Nursing, St. Luke’s International University, 10-1 Akashi cho, Chuo ku, Tokyo, 104-0044, Japan.

Published by Sciedu Press 
ies, a study by Han and $\mathrm{Ahn}^{[3]}$ targeting 100 nursing students who had taken a course in nursing ethics found many ethical problems related to unprofessional conduct by nurses in their professional practice. Meanwhile, a study of nursing students in Turkey revealed failures to protect privacy and other forms of unprofessional conduct, as well as physical and psychological mistreatment of patients by physicians and nurses. ${ }^{[4]}$ Students also perceived ethical problems in the way that information was disclosed to patients, such as being untruthful ${ }^{[3]}$ and providing inappropriate information. ${ }^{[4]}$ In addition to ethical problems involving health care professionals, issues relating to patient quality of life/death and dying, disagreement with a patient's behavior, and persons with HIV and other contagious diseases were also seen. ${ }^{[1,2,6]}$ As these findings indicate, most of the ethical problems encountered by nursing students in clinical practice were related to unprofessional conduct disclosing and explaining information to patients, or, when described in the context of so-called principles of ethics, matters pertaining to patient autonomy, non-maleficence, and veracity.

\subsection{Ethical problems encountered by nursing students in clinical practice-issues involving the students themselves}

There have also been a number of studies on ethical problems between nursing educators and students in clinical practice. Common issues identified by these studies include the following: nursing educators insulting students in front of others, ${ }^{[7,8]}$ displaying an uncaring attitude toward students, ${ }^{[7,9]}$ inconsistent grading such as allowing a student's likeability to influence grading, ${ }^{[7-10]}$ and favoritism toward certain students. ${ }^{[7,8]}$ Inconsistent grading in particular was perceived as a common ethical problem not only by students, but also by nursing educators. ${ }^{[10]}$ Furthermore, a study by Theis ${ }^{[8]}$ identified the ethical problems of ineffective teaching, incompetence as a teacher or nurse, inadequate practical instruction, improper use of students' time, etc. Even when students had doubts about the grades they received, they encountered difficulties and various barriers in communicating these doubts to the nursing educator. For instance, students felt that they might harm their relationship with the faculty or that there was a power differential between themselves and nursing educators. ${ }^{[10]}$ Study findings showed that nursing educators were not aware of these student perceptions and instead believed that they were acting in a fair, considerate, and benevolent manner, thereby encouraging student autonomy. ${ }^{[9]}$ In a study of 39 nursing students, the first experience of clinical practice at a hospital ward was perceived as the most anxious by the students, so negative interactions with health care providers and faculty were a factor in exacerbating this anxiety. ${ }^{[1]}$
These results show that many of the ethical problems that students encountered in clinical practice were reportedly due to nursing educators, the specifics of which were mainly issues related to the student's principle of respect for persons and the principle of justice in grading.

\subsection{Ethical problems encountered by Japanese nursing students in clinical practice}

Several studies have addressed the ethical problems encountered by nursing students in clinical practice in Japan. These issues include a lack of respect for patients in the speech and behavior of students themselves, ${ }^{[12-14]}$ inappropriate speech and behavior by nurses, ${ }^{[15-17]}$ and inadequate explanations by nurses. ${ }^{[18]}$

Ethical guidelines in nursing education were implemented in 2008 by Nursing Education Committee of the Japan Association of Nursing Programs in Universities, ${ }^{[19]}$ and a study focusing on nursing educators is currently being undertaken. Although not limited to clinical practice, Togashi and Takahashi ${ }^{[20]}$ conducted an interview-based survey of 12 nursing educators in which they responded that ethics should be considered when they prioritize their own attitudes over student intentions, when they unintentionally hurt students through their speech and behavior, when they share students' personal information with others without consent, and when they prevent health care providers from losing face without providing feedback as a nursing educator.

Conversely, few studies have examined the ethical problems encountered by students regarding nursing educators and health care providers. Rather, studies are currently limited to ethical problems involving patients and their family members. The researchers are often the nursing educators in charge of clinical practice themselves who analyze student practice records and conduct questionnaire surveys as part of their classes. ${ }^{[15,21]}$ Even if students have doubts about the practical instruction provided by nursing educators and nursing staff, they may not mention these doubts on questionnaire surveys out of fear that doing so might affect their grades. Doi et $a l .{ }^{[22]}$ conducted a study of 132 nursing students showing that, due to this fear, only $19.7 \%$ consulted with nursing educators when they had ethical concerns about clinical practice. In terms of coordination with classroom-based education, Tsuruwaka and Kawakami ${ }^{[23]}$ analyzed the curricula of nursing ethics based on syllabi published on the websites of 200 nursing universities in Japan (as of 2012), and found that only $13 \%$ addressed ethical problems encountered in clinical practice and incorporated them into education; this can hardly be described as adequate education content.

Ethics researchers and researchers with other specialties not 
in charge of clinical practice therefore need to develop a more objective understanding of the types of ethical problems encountered by students in clinical practice as a whole, particularly the issues faced by students themselves and other trainees.

In the present study, a questionnaire survey was conducted on third-year students at a nursing university who had completed 6 months of clinical practice in 2012, 2013, or 2014 to identify the characteristics of ethical problems encountered by university nursing students in Japan in clinical practice and aid research toward the ideal form of education that incorporates ethics in clinical practice. The survey examined ethical problems from the following two perspectives: those involving patients and their family members, and those involving the students themselves and other trainees.

\section{METHOD}

\subsection{Study design}

The present study utilized anonymous, self-administered questionnaires. The questionnaires were composed of multiple choice questions on the frequency of explanations and instruction on ethical problems that students were likely to encounter in clinical practice, opportunities for reflection after clinical practice, and the appropriateness of the education. Students were asked to describe the ethical problems they had encountered to the best of their recollection and without disclosing any personal information or details that could identify their affiliated facilities. The phrase "ethical problems" can be abstract, so the following definition was provided in the present study to facilitate understanding: "Speech and behavior by a person or persons that is disrespectful of the individuality or intent of others, or that poses a threat to life, that is in some way harmful to the lives of others, or that takes away a person's freedom and well-being." Here the term "person" refers to all people involved in clinical practice (i.e., nursing care recipients, nursing students, health care providers, and nursing educators).

\subsection{Participant characteristics and level of study}

The subjects were 274 third-year students at a private singledepartment nursing university located in the central Kanto region of Japan. The students had completed 6 months of clinical practice in $2012(n=98), 2013(n=98)$, or 2014 ( $n=$ 93). Prior to participating in the study, the students had taken the following key subjects relating to ethics. No subjects were dedicated solely to "Nursing ethics". Compulsory subjects were one unit on "Nursing ethics" in the "Fundamental nursing" course in the first year, "Bioethics" in the second year, one unit consisting of a seminar on the Four Boxes proposed by Albert R. Jonsen in the "Community health nursing
II" course in the first semester of the third year, and one unit on ethical support for patients with terminal illnesses in the "Terminal care" course in the fourth year. The only elective subject was "Ethics" offered in the first and second years. In orientation prior to their clinical practice, students received an explanation of their responsibilities, manner, use of the social networking system (SNS), protection of personal information of patients, etc., handling of clinical practice records, violence and harassment, infection prevention and protection, accident prevention, and accident response.

\subsection{Sampling procedures and ethical consideration}

Junior nursing students were invited to participate through recruitment activities which included class announcements in compulsory course. All subjects received a verbal and written explanation of the study objectives, methods, and ethical considerations, and were assured that their participation in the study was voluntary. The questionnaire was anonymous, and students were assured that their personal information would not be disclosed, that by returning the completed questionnaire they would be deemed to have provided their consent, that their responses would not have any effect on their grades, and that they would not be penalized in any way if they chose not to participate in the study. The students were also assured that the questionnaire forms would be strictly controlled, that the anonymized data would be retained for at least 5 years after academic journal publication, at which time it would be destroyed by shredding, and that the anonymity of the data would be maintained, even if published in an academic journal. The study was conducted with the approval of the Research Ethics Committee, St. Luke's International University (No. 12-018).

\subsection{Data analysis}

The multiple choice questions underwent simple tabulation, while in the present study, the main analyses were performed on the ethical problems described by students. The situations in which students described ethical problems were classified into those involving patients and their family members and those involving the students themselves and other trainees.

Ethical problems involving patients and their family members were analyzed from 3 perspectives, namely: < Situation $>,<$ Issue $>$, and $<$ Reason why the student perceived it as problematic $>(<$ Reason $>)$. $<$ Situation $>$ and $<$ Issue $>$ were classified into the following 9 categories in advance because a previous study (Mizuno et al., 1997) suggested that they were highly relevant to routine nursing duties and care: care (maintaining hygiene, excretion, diet, breast feeding, patient education, patient environment and equipment); medical care (medical examination, treatment, medication); physical 
restraints; surgery; collaboration of health care providers (daily briefings, conferences); communication (conversations, greetings); practical instruction (instruction in general, practical consultation, practical interviews); preparation of practical records; and practical assessment.

$<$ Issue > was classified into the following 8 categories: language (individual statements, way of speaking); attitude (manner of interacting, mood, reactive tendency); explanations (explanation of treatment, medical care, nursing, and other general convalescence); medical care and nursing behaviors (the act of medical care/nursing itself that is being undertaken); care methods (methods of nursing care); management methods (management of people and materials); teaching methods (teaching methods for instructing students on clinical practice); and assessment methods for students. As shown in previous studies, ${ }^{[1,2,4]}$ many students identified the problem of unprofessional conduct, so $<$ Reason $>$ was classified according to the Code of Ethics for Nurses established by the Japanese Nursing Association. ${ }^{[24]}$

$<$ Situation $>$ and $<$ Issue $>$ were analyzed for problems involving students themselves and other trainees, as well as for problems involving patients and their family members, while $<$ Reason $>$ was analyzed using the three major ethical principles proposed by Theis, ${ }^{[8]}$ namely, respect for persons, justice, and beneficence. ${ }^{[25]}$

\section{Results}

\subsection{Number of ethical problems encountered during clinical practice}

Questionnaire responses were received from 58 students, for a response rate of $21.2 \%$ of the total study population $(26 \%$ in $2012,15 \%$ in 2013, and $19 \%$ in 2014). These 58 responses were included in the analysis. The ethical problems freely described in the questionnaires were derived from a total of 198 situations. Problems involving patients and their family members were derived from 89 situations, and problems involving students themselves and other trainees were derived from 102 situations, while other types of problems arose from 7 situations.

The number of ethical problems perceived by students involving patients and their family members was $0(17 \%)$, $1-2(55 \%), 3-4$ (19\%), 5-6 (5\%), 7-9 (2\%), and $\geq 10(2 \%)$. Meanwhile, the number of ethical problems perceived by students, involving students themselves and other trainees, was $0(10 \%), 1-2(52 \%), 3-4(17 \%), 5-6(14 \%)$, and $\geq 10$ (7\%). These results show that $74 \%$ of students had encountered ethical problems involving patients and their family members. Furthermore, $69 \%$ of students had encountered ethical problems involving themselves or other trainees, and
$21 \%$ of students had encountered 5-10 problems.

\subsection{Instruction and classes by nursing educators on eth- ical problems}

In response to the question on explanations and instruction on ethical problems either before or during clinical practice, $14 \%$ of respondents selected "Often", $21 \%$ selected "Sometimes", 46\% selected "Rarely", and 19\% selected "Never". The combined percentage of respondents who selected either "Rarely" or "Never" was therefore $65 \%$. In response to the question on explanations and instruction on how to respond to and deal with ethical problems, $12 \%$ of the respondents selected "Often", 23\% selected "Sometimes", $41 \%$ selected "Rarely", and 24\% selected "Never". Thus, the combined percentage of respondents who selected either "Rarely" or "Never" was again 65\%, indicating an awareness among students that prior explanation and instruction on ethical problems was lacking. In response to the question of whether the classes were appropriate for considering the ethical problems encountered in clinical practice, $4 \%$ of respondents selected "Appropriate", 36\% selected "Somewhat appropriate", 50\% selected "Not really appropriate", and 10\% selected "Inappropriate". The combined percentage of respondents who selected either "Not really appropriate" or "Inappropriate" was $60 \%$, thus highlighting issues in the content of classes.

\subsection{Opportunities for reflection}

Students who responded that they had opportunities for reflecting upon ethical problems accounted for $98 \%$ of all respondents, indicating that the majority of students did in fact have such opportunities. Specifically, these opportunities for reflection arose through self-deliberation (28\%), while talking with friends (28\%), while summarizing the clinical practice $(14 \%)$, in individual interviews after the clinical practice $(13 \%)$, while talking with parents $(10 \%)$, in class after the clinical practice (3\%), and in other situations (10\%). This finding shows that $66 \%$ and $30 \%$ of the opportunities for reflecting upon ethical problems arose outside and within the context of class, respectively. Therefore, it appears that currently, these reflections tend to be limited to discussions of one's own experiences and to occur outside of class.

\subsection{Ethical problems involving patients and their family members}

Of the 198 situations of ethical problems described by the 58 respondents, 89 were problems that involved patients and their family members. The parties who were identified as engaging in ethically problematic behavior were nursing staff $(71 \%)$, other health professionals $(10 \%)$, students $(4 \%)$, physicians $(3 \%)$, nursing educators $(3 \%)$, others $(3 \%)$, and unknown (4\%). The recipients of this ethically problematic 
behavior were the patients $(91 \%)$, family members $(6 \%)$, residents of facilities for the elderly (2\%), and puerperants (1\%). Moreover, $46 \%$ of these persons had difficulty communicating (i.e., those with impaired consciousness, those with dementia, infants, and those with a mental disorder).

The $<$ Situation $>$ in which these problems arose was care (45\%), communication (38\%), practical instruction (9\%), collaboration between health care providers $(3 \%)$, medical care (2\%), physical restraint $(2 \%)$, and surgery $(1 \%)$. The $<$ Issue $>$ to which these problems belonged was language (40\%), care methods (26\%), medical care and nursing behaviors (9\%), explanations $(8 \%)$, teaching methods $(8 \%)$, attitude $(7 \%)$, and management methods $(2 \%)$. When viewed in the context of the Japanese Nursing Association's code of ethics, the $<$ Reason $>$ was a lack of respect for persons (46\%), which relates to Article 1 of the Code, failure to protect and safeguard from inappropriate decisions and behavior (34\%), which relates to Article 6 of the Code, lack of consideration for privacy (10\%), which relates to Article 5 of the Code, inadequate collaboration with other health care providers (4\%), which relates to Article 9 of the Code, failure to protect the rights of people to information and self-determination (3\%), which relates to Article 4 of the Code, lack of basis of a relationship of trust (2\%), which relates to Article 3 of the Code, and failure of nurses to take responsibility for the nursing care they provide (1\%), which relates to Article 7 of the Code. A breakdown of the 62 situations that arose due to a lack of respect for persons is as follows: lack of respect for the individuality of others $(64 \%)$, treating people like objects $(10 \%)$, coercive behavior $(8 \%)$, inconsiderate toward the shame of others $(6 \%)$, ignoring people $(5 \%)$, lack of respect for the intent of others $(5 \%)$, and limiting the freedom of action of others $(2 \%)$.

The situations described in the questionnaire contained the following sentiments of the students toward the problem.

- The nursing staff assumed that the patient did not understand what was going on due to a lack of awareness, and treated the patient harshly.

- The nurse performed aspiration forcefully, even though the patient's nose was bleeding. I felt very sorry for the patient, who appeared to be in a great deal of pain and suffering.

- Busy nurses are unable to respond to all of the patient's statements, so the situation could not be helped.

As seen above, the respondents did not consider the nature of these ethical problems or conceive approaches to deal with them, and were instead limited to criticizing health care providers and expressing empathy or resignation.

\subsection{Ethical problems involving students themselves and} other trainees

Ethical problems involving the students themselves or other trainees accounted for 102 of the 198 situations. The parties who were identified as engaging in ethically problematic behavior were nursing educators (70\%), nursing staff (26\%), other health care professionals $(2 \%)$, patients $(1 \%)$, and unknown (1\%). The recipients of this ethically problematic behavior were the students themselves (63\%), other trainees $(34 \%)$, and practical training groups $(4 \%)$. The $<$ Situation $>$ in which these problems arose were practical instruction (72\%), communication (23\%), practical assessment (3\%), and preparation of practical records $(3 \%)$. The $<$ Issue $>$ to which these problems belonged was teaching methods (43\%), language (34\%), attitude (20\%), assessment methods (2\%), and explanations $(1 \%)$.

Regarding $<$ Reason $>$, when viewed in the context of the major ethical principles of respect for persons, justice, and beneficence, the percentage of students who perceived that the issues were not based on each of these principles was $38 \%$ for respect for persons, $6 \%$ for justice, and $56 \%$ for beneficence. The principle of respect for persons was classified into lack of respect for the individuality of others (48\%), coercive behavior $(41 \%)$, ignoring people $(7 \%)$, lack of respect for the intent of others $(3 \%)$, and speaking about others in a derogatory manner $(2 \%)$. The principle of beneficence was classified into inappropriate instruction (37\%), inflicting suffering (18\%), and relationship not based on trust (1\%). Specifically, students perceived inappropriateness in the issues above as follows: interference with student learning (25\%; e.g., overly long lectures such that clinical practice was reduced to half a day), emotional responses $(22 \%, e . g$., shouting, bullying, laughing, or changing responses according to one's mood), negative responses in front of others (20\%), lack of appropriate breaks $(11 \%$, e.g., not providing a lunch break, making students wait for interviews until 8 p.m.), making associations with the earning of academic credits $(6 \%)$, lack of consistent instruction among nursing educators $(5 \%)$, demanding copious amounts of practical work records $(5 \%)$, inadequate communication (5\%), and lack of consideration for relationships among students (3\%, e.g., making statements that isolated certain students within practical training groups). In terms of inflicting suffering, students described 3 cases of negative feedback on a daily basis and absence as a result of falling sick from acute gastritis, etc. Ethical problems relating to the principle of justice were unfair treatment $(4 \%)$ and lack of transparency in grading (2\%). The findings showed that many students tended to remain silent about this problem.

- I couldn't make any comments to the nursing educator 
when my grades were not up to scratch.

- When I stated an opposing opinion, I felt pressure that my grades would be affected. In the latter half of the clinical practice, students began sharing the view that the way to innocuously pass the practice was to obediently comply with the nursing educator's words by nodding and agreeing.

- Many students regard the clinical practice grade as important, so they treat the nursing educator's words as the infallible truth.

These comments show that students obviously place utmost priority on obtaining a good grade and academic credit, and are therefore unwilling to behave in a way that might jeopardize either of these.

\section{Discussion}

\subsection{Characteristics of ethical problems encountered by Japanese nursing students}

The present study demonstrated that Japanese nursing students encounter various ethical problems in clinical practice that involve patients, the students themselves, and other trainees; however, the most common problems involve those of nursing educators toward students. As previously mentioned, there is a paucity of research in Japan examining the ethics between nursing educators and students and nursing staff and students in clinical practice from the perspective of the students. This is because surveys are typically conducted by the nursing educators in charge of clinical practice and often involve the analysis of practical work records, making it inherently difficult to shed light on ethical problems as perceived by the students.

In a study by Theis, ${ }^{[8]}$ participants described 107 situations of unethical conduct by nursing educators during clinical practice, of which $58 \%$ related to the principle of respect for persons, $22 \%$ related to the principle of justice, and $20 \%$ related to the principle of beneficence. In the present study, respondents described 102 situations, among which, 38\% related to the principle of respect for persons, $6 \%$ related to the principle of justice, and $56 \%$ related to the principle of beneficence. One feature of the present study was that, although the results relating to respect for persons were similar to those of previous studies, many of the ethical problems were associated with the principle of beneficence, and few were associated with the principle of justice. Rather than issues related to grading, many students held doubts about the appropriateness of practical instruction provided by nursing educators and nursing staff. The findings also highlighted major issues on basic matters related to respect for student individuality by nursing educators and nursing staff in the form of belittling speech and behavior and coercive behavior. A previous study has shown that students want mutual respect and veracity from nursing educators. ${ }^{[26]}$

In terms of ethical problems involving patients and their family members, our finding that the majority of these issues were caused by nurses is consistent with previous studies from the U.S., South Korea, and Turkey. ${ }^{[1-4]}$ Much of the problematic conduct described by respondents focused on the basic attitudes of nurses and respect for the patient's individuality, including methods for assisting patients in their daily activities of maintaining hygiene, excretion, and feeding, as well as the type and way of speaking that nursing staff used toward patients. A study by Kelly ${ }^{[5]}$ also found that in clinical practice, students were keenly aware of the importance of respecting the patient's individuality. Students learn about basic attitudes that nurses should possess, such as patient's rights and consideration for privacy, from their first year. In that sense, students are therefore likely to notice what they have learned at university. As the present results show, students also focused on the ideal form in which nursing should be provided to patients who have difficulty communicating. Students recognize the importance of the nursing staff to protect the rights of vulnerable patients. The fact that respondents described a lack of respect for patients who had difficulty communicating holds clinical implications in terms of the basic attitudes of nursing staff and the ideal form of communication. On the other hand, few respondents described the situations in surgeries and informed consent to patients, which are both closely connected to clinical care. Previous studies have identified ethical problems in the ideal form of the way that physicians, etc., report facts and share information, ${ }^{[3,4]}$ but few students in the present study described such situations. This could be attributed to the fact that in clinical practice, students are generally not present when physicians make these representations to patients. The questionnaires also contained few responses on the inability to provide appropriate care to patients due to the students' relative inexperience and lack of knowledge. A previous study conducted in Japan ${ }^{[14]}$ managed to identify this issue, likely because it analyzed data obtained from students' practical work records.

\subsection{Suggestions for ethics education in future clinical practice}

Based on the present study, we intend to propose the following 4 themes for ethics education in future clinical practice. The first theme is helping students to understand and interpret the ethical problems that they encounter in clinical practice. The way that students perceived ethical problems was limited to criticism of nurses and other emotive expressions. It is

ISSN 1925-4040 E-ISSN 1925-4059 
important for students not only to recognize ethical problems in clinical practice, but also to identify the nature of these problems and think about how to deal with them as nursing staff. Nursing educators must therefore help students to achieve this level of understanding. Both the present study and a previous Japanese study ${ }^{[22]}$ found that students rarely consulted with nursing educators when reflecting upon ethical problems. It is therefore crucial to actively encourage students to consult with their nursing educators. Meanwhile, nursing educators must make an effort to communicate with their students as people and without intimidation. Nursing staff can help students to understand and interpret ethical problems by explaining the decisions that inform their own nursing behaviors and describing the processes by which they arrive at these decisions. These results suggest that nursing educators and clinical staff need to get together and rethink the aims of clinical practice and the role of trainees.

The second theme is to strengthen ties with classroom-based ethics education. A previous study has demonstrated that intramural learning and clinical practice are not effectively linked when it comes to ethics education. ${ }^{[27]}$ In Japan, 75\% of nursing ethics courses are taken before the students undergo clinical practice. ${ }^{[23]}$ It would therefore be preferable to provide academic units that allow students to consider ethical issues after clinical practice, and to hold conferences after clinical practice where students can consider any ethical problems they encountered. Students are more likely to notice issues that they have already learned about through classes, so case studies and role play on ethical problems that they are likely to encounter in clinical practice, implemented in advance, can be expected to serve as effective learning tools.

The third theme is the development of a consultation system, and the fourth theme is the application of faculty development education. The nature of the nursing educator-student and nursing staff-student relationship in practical instruction means that it is difficult for students to consult with nursing educators on ethical problems. It is therefore necessary to develop a consultation system staffed mainly by individu- als who are not involved in clinical practice, and in which students are assured that they will not be penalized in any way for using the system. The fourth theme of faculty development education would be useful in providing learning opportunities to raise awareness on the ideal form that practical instruction should be conducted and issues of harassment by recognizing the unethical nursing educator and nursing staff conduct perceived by students as an issue pertaining to the entire faculty.

The present study targeted nursing students at a single university across a period of 3 years, and the results only reflect student perspectives; therefore, further research is needed to clarify the types of ethical problems as perceived by nursing educators and investigate bidirectionally. The ethical nature of clinical practice warrants close scrutiny because it involves interactions with a broad range of people. ${ }^{[28]}$

\section{Conclusion}

Clinical practice is an indispensable part of nursing education. The configuration of clinical practice provides students with education with a comprehensive insight into nursing by allowing them to interact not only with patients and their family members, but also with nursing staff, physicians, and various other health care providers. Students perceive many ethical issues in clinical practice, and nursing educators must help them develop these perceptions and encourage them to understand and interpret ethical problems. In developing an educational environment for clinical practice, nursing educators therefore need to constantly consider how they can interact with students in a manner that is respectful of their humanity.

\section{ACKNOWLEDGeMENTS}

This study was supported by a Grant-in-Aid for Young Scientists (B) from the Japan Society for the Promotion of Science (Grant No. 24790514).

\section{CONFlicts OF INTEREST Disclosure}

The author declares that there is no conflict of interest statement.

\section{REFERENCES}

[1] Cameron ME, Schaffer M, Park HA. Nursing students' experience of ethical problems and use of ethical decision-making models. Nursing Ethics. 2001; 8(5): 432-447. PMid:16004097

[2] Park HA, Cameron ME, Han SS, et al. Korean nursing students' ethical problems and ethical decision making. Nursing Ethics. 2003; 10(6): 638-653. PMid:14650482 http://dx.doi.org/10.1191 /0969733003ne653oa
[3] Han SS, Ahn SH. An analysis and evaluation of student nurses' participation in ethical decision making. Nursing Ethics. 2000; 7(2): 113-123. PMid:10986936

[4] Erdil F, Korkmaz F. Ethical problems observed by student nurses. Nursing Ethics. 2009; 16(5): 589-598. PMid:19671645 http://dx .doi.org/10.1177/0969733009106651

[5] Kelly B. The "real world" of hospital nursing practice as perceived by nursing undergraduates. Journal of Professional Nursing. 1993; 
9(1): 27-33. http://dx.doi.org/10.1016/8755-7223(93) 9 0083-0

[6] Nolan PW, Markert D. Ethical reasoning observed: a longitudinal study of nursing students. Nursing Ethics. 2002; 9(3): 243258. PMid: 12035430 http://dx.doi.org/10.1191/096973300 2ne507oa

[7] Savage JS, Favret JO. Nursing students' perceptions of ethical behavior in undergraduate nursing faculty. Nurse Education Practice. 2006; 6: 47-54. PMid:19040855 http://dx.doi .org/10.1016/j.nep r. 2005.08 .002

[8] Theis EC. Nursing students' perspectives of unethical teaching behaviors. Journal Nursing Education. 1988; 27(3): 102-106. PMid:2832559

[9] Schaffer MA, Juarez M. An ethical analysis of student-faculty interactions. Nurse Educator. 1993; 18(3): 25-28. PMid:8336853 http://dx.doi.org/10.1097/00006223-199305000-00012

[10] Schmiz K, Schaffer M. Ethical problems encountered in the teaching of nursing: student and faculty perceptions. Journal of Nursing Education. 1995; 34(1): 42-44.

[11] Kleehammer K, Hart L, Keck JF. Nursing students' perceptions of anxiety-producing situations in the clinical setting. Journal of Nursing Education. 1990; 29(4): 183-187. PMid:2159066

[12] Kaneko M. Nursing ethics in nursing students: analysis of nursing ethics in 141 nursing students after 3 years of clinical practice. Journal of the Center for Professional Nursing (Kanagawa University of Human Services). 2006; 31: 85-91. Japanese.

[13] Ohata M, Hara S. Ethical dilemmas experienced by nursing students in gerontological nursing clinical practice. Shimane Journal of Medical Science. 2007; 30: 1-9. Japanese.

[14] Mizuno T, Imagawa J, Hasegawa M. A study on nursing dilemmas and nursing ethical education: analysis of nursing dilemmas experienced by nursing students in their first clinical practice. The Bulletin of Saitama Prefectural University College. 1997; 22: 55-63. Japanese.

[15] Ono H, Doi H, Yamashita T, et al. [Ethical dilemmas encountered in nursing practice and educational subjects]. Journal of Japanese Nursing Association: Nursing Administration. 2011; 41: 156-159. Japanese.

[16] Sekiya Y. Ethical questions of nursing students in nursing practices. Journal of Japanese Nursing Association: Nursing Education. 2011; 41: 90-92. Japanese.
[17] Suganuma S, Ando T, Matsumoto Y. Study of ethical judgments of nursing students. Journal of Japanese Nursing Association: Nursing Education. 2010; 40: 48-50. Japanese.

[18] Matsugi K, Miyajima A. Ethical concerns captured by nursing students and moral values of nurses. Annual Report of School of Health Sciences Faculty of Medicine, Kyoto University. 2007; 4: 39-44. Japanese.

[19] Nursing Education Committee of the Japan Association of Nursing Programs in Universities. A code of ethics in nursing education, Japan Association of Nursing Programs in Universities. 2008. Available from: http://www.janpu.or.jp/umin/kenkai/rinr ishishin08.pdf

[20] Togashi K, Takahashi M. Analysis of behavior in the scenes made by nursing faculty which seemed to be blamed for ethically. Journal of North Japan Academy of Nursing Sciences. 2008; 10: 59-66. Japanese.

[21] Kojo S, Kinoshita K, Umamoto T. Analysis of nursing dilemmas experienced by nursing students in elderly nursing practice. The Bulletin of Niimi College. 2004; 25: 63-71. Japanese.

[22] Doi H, Ono H, Yamashita T, et al. Students responses to the dilemmas in nursing practice. Journal of Okayama Research of Nursing Education. 2010; 34: 9-12. Japanese.

[23] Tsuruwaka M, Kawakami Y. Examination of nursing ethics education in nursing bachelors programs from contents of syllabuses. Journal of Japanese Nursing Ethics. 2013; 5: 71-75. Japanese.

[24] Japanese Nursing Association. Code of ethics for nurses. 2003. Available from; http://www.nurse.or.jp/nursing/practice/rin ri/rinri.html

[25] Beauchamp TL, Childress JF. Principles of biomedical ethics (7th ed.). New York: Oxford University Press; 2012.

[26] Viverais-Dresler G, Kutschke M. RN students' ratings and opinions related to the importance of certain clinical teacher behaviors. Journal of Continuing Education in Nursing. 2001; 32(6): 274-282. PMid:11868719

[27] Epstein I, Carlin K. Ethical concerns in the student/preceptor relationship: a need for change. Nurse Education Today. 2012; 32 897-902. PMid:22503294 http://dx.doi.org/10.1016/j.ned t.2012.03.009

[28] Fry ST, Johnstone MJ. Ethics in nursing practice: a guide to ethical decision making (3rd ed.). Oxford; 2008, Blackwell. 